\title{
Strengthening prevention in communities through systems change: lessons from the evaluation of Healthy Families NZ
}

\section{Anna Matheson $\mathbb{D}^{1, *}$, Mat Walton ${ }^{2}$, Rebecca Gray ${ }^{1}$, Nan Wehipeihana ${ }^{3}$, and Jonathon Wistow ${ }^{4}$}

\author{
${ }^{1}$ School of Health, Victoria University of Wellington, New Zealand, ${ }^{2}$ Institute for Environmental Science \\ and Research (ESR), New Zealand, ${ }^{3}$ Research Evaluation Consultancy, Wellington, New Zealand and \\ ${ }^{4}$ Department of Sociology, Durham University, UK \\ ${ }^{*}$ Corresponding author. E-mail: anna.matheson@vuw.ac.nz
}

\section{Summary}

This article presents the findings from the first 3 years of the evaluation of Healthy Families NZ, a systems-change intervention to prevent chronic diseases in 10 communities. The initiative, which builds on existing prevention activities, aims to strengthen the health prevention system through evidencedriven action to enable people to make good food choices, be physically active, smoke-free and free from alcohol-related harm. Key investment areas are a dedicated systems thinking and acting health promotion workforce, and activating leaders who can influence transformational change. The evaluation to date has found the initiative is being implemented with integrity. Evidence indicates a shift towards greater action on prevention, and the prevention system being strengthened. Māori ownership has been enabled, and prioritizing equity has led teams to utilize methods that amplify diverse local perspectives. There is progress on developing a flexible workforce through adaptive learning, flexible resources, professional development and a responsive National team. There is also progress in activating local leadership and empowering local teams. The initiative design has explicitly taken into account the context of complexity within which it is being implemented. It has evolved to focus on action that can accelerate sharing information and practices within communities, and between policy and decision-makers. Healthy Families NZ and its evaluation have been refunded to 2022. This provides an important opportunity to gather further insight into effective ways to strengthen the community agency and trust needed to promote and deliver evidence-based action on prevention.

Key words: community-based intervention, chronic illness, systems change, public health evaluation, evidence-based health promotion

\section{INTRODUCTION}

Chronic diseases are on the rise globally and contribute substantially to inequalities in health. How to reduce the incidence and impact of chronic disease is a pressing health policy challenge, widely recognized as complex. Acting on complexity through systems-related methods is increasingly seen as necessary within public health (Tremblay and Richard, 2014; Hawe, 2015; Salway and 
Green, 2017). Greater consideration is also being given to social complexity in relation to how interventions are designed and evaluated (Shiell et al., 2008; Eppel et al., 2011; Matheson, 2016; Rutter et al., 2017). There are, however, few examples of health interventions designed explicitly drawing on theories of complex systems. This article presents the findings from an evaluation of a systems change-focused intervention to prevent chronic diseases, called Healthy Families NZ, which is being carried out in 10 communities in Aotearoa New Zealand (NZ).

\section{LARGE-SCALE PUBLIC HEALTH INITIATIVES-CONTEXT MATTERS}

Healthy Families NZ is being implemented at a time when there is growing appreciation of the need for a paradigm shift away from linear, siloed approaches to improving health, towards complex systems thinking (Braithwaite, 2018; Greenhalgh and Papoutsi, 2018). Sophisticated conceptualizations of health intervention, grounded in complex systems, are now being developed and articulated. Hawe, for example, argues that interventions are 'events in a system' (Hawe et al., 2009) and need to be able to adapt to the specific social, economic, cultural and geographic circumstances of a community. A feature of context is sensitivity to initial conditions, which describes the impact of context over time. This means outcomes may be very different for communities undergoing similar interventions (Rickles, 2009). This was apparent in a multi-community health project in NZ implemented in early 2000. The nature of existing relationships between communities and local and central government actors led to a very different experience of the programme for each of the four communities (Matheson et al., 2009). A more recent evaluation of the Big Local community empowerment programme for action on social inequalities, in the UK, also identified the critical role of local context in meeting the programme aims (Orton et al., 2017).

Evidence continues to grow of the need for a comprehensive and coordinated approach to chronic disease prevention, and one that is able to be sustained over the longer-term (Nugent et al., 2018). There are a number of examples of integrated community and area-based interventions, and other large-scale initiatives globally that have aimed to improve health and equity, including for chronic disease. Lessons identified from these initiatives highlight a need to think more explicitly about social complexity, and how human systems behave. One well-documented experience has been the success in North Karelia, Finland, of improving cardiovascular disease (CVD). While the North Karelia experience showed improvement in CVD outcomes over decades, the pathway to this success was one that was not planned. What actually occurred was a long process of multi-level actions over time that were related to, and influenced, each other (Vartiainen, 2018).

When large-scale interventions are planned without considering complexity, they suffer a number of challenges (Galea et al., 2000; Judge and Bauld, 2006; De Leeuw, 2009; Cheadle et al., 2011; Stafford et al., 2014; Petticrew et al., 2019). For a start, evaluating them is tricky. Because they usually span different community contexts, and take different forms, attributing specific impacts can be difficult, if not impossible-especially in the short-term (Walton, 2014). When the expected causal connection is over a long period, as in the case for prevention, the evaluation approach needs to be cognizant of this challenge.

We also know that leaders, leadership and champions play an important role in achieving systems change-but frequently there is too much reliance on the stability and capacity of individuals rather than focusing on wider institutional factors (Murphy et al., 2017). Even more fundamentally, these types of initiatives are also vulnerable to political change which means many are discontinued before their long-term efficacy has been established.

\section{THE INITIATIVE BEING EVALUATED: HEALTHY FAMILIES NZ}

Healthy Families NZ is a government-funded initiative which takes a systems change approach to strengthening community leadership and organization to prevent chronic disease. It builds on existing action underway in the community to strengthen the health prevention system through evidence-driven action to enable people to make good food choices, be physically active, smokefree and free from alcohol-related harm.

The initiative is being carried out in 10 different geographic communities around NZ-Invercargill, Christchurch, Lower Hutt, Whanganui-RangitikeiRuapehu, Rotorua, East Cape, Manukau, ManurewaPapakura, Waitakere and Far North. These are predominantly areas with higher than average rates of risk factors for preventable chronic diseases and/or high levels of socio-economic deprivation. The areas are a mixture of urban and rural, and within each of these communities a locally based Lead Provider (LP) is responsible for implementing the initiative. The tendering process to select LPs prioritized organizations who were best placed to lead change in their communities. 
Three types of organization were selected as LPs (i) Māori and iwi organizations owned and/or run by a majority of people of Māori (indigenous) ethnicity which can be formally linked with local iwi (tribe); (ii) Regional Sports Trusts, which are charitable Trusts promoting physical activity through sports and recreation; (iii) Local Councils, with powers and responsibilities for local facilities, such as local roads and footpaths, community venues, building and planning, water, sewerage, parks and reserves, rubbish collection and community development Contracts with LPs began from September 2014, for an initial term of 4 years (to June 2018) with contracts recently being renegotiated and extended to 2022.

The key investment areas of the intervention are in a dedicated systems thinking and acting health promotion workforce and activating local leadership to influence transformational change through local Strategic Leadership Groups (SLGs). SLGs are chaired by a senior person from the LP, and comprise people with diverse spheres of influence, usually senior people from health, local government, Māori, business and education sectors and a representative from commissioning agency the Ministry of Health (MoH).

Investment is also guided by five building blocks for a strong prevention system, adapted from the WHO's building blocks for a strong health system (Adam et al., 2009). These are workforce, leadership, relationships and networks, resources and knowledge and data. Underpinning the initiative is also a set of principlesimplementation at scale, adaptation, collaboration for collective action, experimentation, equity, leadership and line-of-sight. These seven principles are intended to promote shared purpose and were adapted from a similar initiative in Australia, Healthy Together Victoria (Matheson et al., 2018c).

The $\mathrm{MoH}$ has approached this initiative differently from other activities it funds, being more explicitly context—and complexity—oriented. A small dedicated team within the $\mathrm{MoH}$ has had a uniquely hands-on relationship with the SLGs and local teams, as well as a more open and responsive contract reporting approach. $\mathrm{MoH}$ team members also see themselves as having a role in facilitating more joined-up national action to influence and enable local action.

\section{MATERIALS}

The overall design of the evaluation is a comparative case study. Rich case studies of each Healthy Families NZ community and of the National perspective have been developed at two points in time, 2 years apart
(View 12016 and View 2 2018). The method involved a systematic process of comparison, including the use of Qualitative Comparative Analysis (QCA). The detail and rationale for the overall design has been explained in another paper (Matheson et al., 2018b).

\section{The case-building process}

For each of the 10 communities, diverse data sources were brought together to create a rich detailed story of the implementation of the initiative and key contextual qualitative and quantitative features. Before being finalized, case studies were given to participants in each location team to provide feedback and refine the accuracy and interpretation of the data.

\section{SUMMARY OF DATA SOURCES}

\section{Key informant interviews}

Semi-structured key informant interviews were carried out with members employed within each local team, SLG members, selected collaborating organizations in each location, and national stakeholders (View 1-120, interviews; View 2-107, interviews). The $\mathrm{MoH}$ team and other stakeholders were also interviewed to provide a national perspective (View 1, seven interviews; View 2 , eight interviews).

\section{Healthy Families NZ team manager phone interviews}

Regular phone interviews $(n=65)$ to reflect on progress and challenges were conducted with Managers in each community.

\section{Survey of stakeholders}

Three versions of an online survey were developed in each of the 10 communities, for View 2 only, aiming to elicit further perspectives on the initiative's implementation. Surveys were sent out progressively to each community from October to early November 2017. While there was variation overall there were 326 responses to the partner organization survey (response rate of $38 \%$ ), 57 responses to the workforce survey (response rate of $66 \%$ ) and 35 responses to the Leadership Group survey (response rate of $47 \%$ ). These response rates were adequate for the survey's purpose.

\section{Documents}

Key documents were collected, including service contracts and Performance Monitoring Reports submitted by communities to the MoH every 6 months. 
Location-specific quantitative indicators of chronic disease risk factors

Quantitative indicators of chronic disease risk factors were developed using a range of survey and administrative data sources, including the New Zealand Health Survey and B4 School Check. It is both too soon to see attributable change in the location level chronic disease risk factor indicators, and requires an involved interpretation. We will discuss this, and the method, in another paper.

\section{ANALYSIS}

The findings presented in this paper come from analysis of the View 2 case studies and focus on (i) changes in themes between View 1 and View 2, and; (ii) similarities and differences in themes across communities.

All data types described above (except for the quantitative indicators) were considered in identifying changes within each case study. We used two complementary methods (i) Crisp Set QCA; and (ii) thematic analysis of qualitative and document data. QCA is a method for systematic comparison across cases. It is gaining popularity for work requiring explicit recognition of social complexity, including evaluations of public health interventions (Blackman et al., 2011, 2013; Warren et al., 2014). The QCA and findings will be discussed in depth in another article. Here, we show the qualitative indicators developed for the QCA and the related thematic analysis of the case studies.

\section{Qualitative indicator development and judgements process}

Through a systematic and consultative process with the local teams, MoH and our Māori Advisory Group, we developed qualitative indicators to feed into the QCA. Indicators, developed for each of the Buildings Blocks and for the Prevention System, helped us judge whether an outcome (or condition) is present or absent in each case. We designed the data collection to address these indicators by including relevant questions in the interviews and surveys. The research team made qualitative judgements about the extent to which each community case met criteria developed for each indicator. In line with crisp set QCA, we allocated binary categories ( 1 or 0 ) to each of the cases where 'present' $=(1)$ or 'absent' $=(0)$. These represent differences in kind, as opposed to differences in degree. Cases' membership of a category ( 1 or 0$)$ is referred to in QCA terminology as a 'condition'.

\section{Thematic analysis of the case studies (interviews, documents and survey)}

We conducted a thematic analysis on the case study data to understand the 'story' presented relevant to the implementation and outcomes of the initiative. Each case study was analysed separately and themes were identified. This involved identifying, coding and categorizing the primary patterns in the data (Patton, 2002). The qualitative analysis software Dedoose was used to organize the thematic codes. Multiple researchers were involved in this process to verify interpretations of the data, then to identify the shared and divergent themes across all the case studies.

\section{FINDINGS}

This section illustrates the judgements made for the qualitative indicators developed to determine whether the prevention system has been strengthened, and to consider the quality of the implementation in each location. We also reflect on themes developed from analysis of View 2 case studies.

\section{Strengthening the prevention system}

Almost universally, participants believed that Healthy Families NZ had strengthened the prevention system. Numerous actions and changes in mindsets have occurred, as captured in Table 1, giving weight to these perspectives. There was also evidence of many local successes. Common areas included workplace well-being, wai/water-only movement, kai/food systems, proliferating community gardens, supporting enterprise within local food systems, healthier city events, smoke-free policies, tree planting and other sustainability and resilience projects.

We developed criteria for two outcomes of systems change for a strengthened prevention system (Matheson et al., 2018b). First, Prevention Infrastructure, requiring evidence of an increase in local organizations focusing on prevention and healthier practices, including through policy changes, changes in the built environment and additional resources dedicated to prevention. Second, Prevention Attitudes and Paradigm, requiring evidence of an increased commitment to prevention or seeking out opportunities to collaborate with other organizations for the purpose of prevention.

Table 1 shows, for Prevention Attitudes and Paradigm, that 9 of the 10 communities demonstrated both their own understanding of the prevention system, and other organizations increasingly understanding prevention. This included knowing how they could contribute to prevention and showing willingness to change organizational practices to promote health. Common examples included increased commitment of staff resources to collaborative, health-focused projects. 
Table 1: Outcome judgements of a stronger prevention system ${ }^{\mathrm{a}}$ and Building Block Conditions ${ }^{\mathrm{b}}$ for each Healthy Families NZ community

\begin{tabular}{|c|c|c|c|c|c|c|c|}
\hline $\begin{array}{l}\text { Healthy Families } \\
\text { NZ communities }\end{array}$ & $\begin{array}{l}\text { Prevention attitudes } \\
\text { and paradigm }\end{array}$ & $\begin{array}{l}\text { Prevention } \\
\text { infrastructure }\end{array}$ & Workforce & Leadership & $\begin{array}{l}\text { Relationships } \\
\text { and networks }\end{array}$ & Resources & $\begin{array}{l}\text { Knowledge } \\
\text { and data }\end{array}$ \\
\hline Community 1 & 1 & 0 & 0 & 0 & 0 & 1 & 1 \\
\hline Community 2 & 0 & 0 & 0 & 0 & 0 & 0 & 0 \\
\hline Community 3 & 1 & 0 & 1 & 0 & 1 & 0 & 0 \\
\hline Community 4 & 1 & 1 & 1 & 1 & 1 & 1 & 1 \\
\hline Community 5 & 1 & 1 & 1 & 1 & 0 & 1 & 1 \\
\hline Communities 6 and $7^{c}$ & 1 & 1 & 0 & 0 & 1 & 1 & 1 \\
\hline Community 8 & 1 & 0 & 0 & 1 & 0 & 1 & 0 \\
\hline Community 9 & 1 & 1 & 1 & 0 & 1 & 1 & 1 \\
\hline Community 10 & 1 & 1 & 1 & 1 & 1 & 1 & 1 \\
\hline
\end{tabular}

${ }^{a}$ Each community was judged against the two indicators we identified of a stronger prevention system: prevention attitudes and paradigm, and prevention infrastructure-'present' $=(1)$ or 'absent' $=(0)$.

'Each community was categorized against each of the Building Blocks of a strong prevention system with 'present' = (1) or 'absent' = (0). The criteria by which Building Block conditions were categorized as either present or absent, should not be read as meaning either 'excellent' or 'poor'. Rather this categorization relates to consistency or inconsistency in implementation.

${ }^{\mathrm{c} C o m m u n i t i e s} 6$ and 7 are shown together as the team was combined to cover the two community areas.

Six of the 10 communities demonstrated increased capacity in Prevention Infrastructure. For example, some teams secured additional investment in water fountain infrastructure in public spaces from local Councils and philanthropic sources. Teams also helped facilitate the introduction of 'water-only' and other nutritional policies, local smoke-free policies and, in one community, additional cycle infrastructure.

\section{Quality of implementation}

Implementation of the initiative has been variable, but largely consistent with the intent of the initiative design. All communities took a significant lead-in time to recruit workforce, establish SLGs and understand their opportunities for action. During the second year we saw increased community action in most communities, with momentum building further by the third year. Stability in workforce and SLG was important for building momentum, but so too was successful early demonstration of collaborative and systems-focused activity. Challenges in the recruitment, stability and cohesion of the workforce were more pronounced in the communities with higher socio-economic deprivation. This partly relates to fewer qualified candidates being available due to people leaving these areas for better employment opportunities, as well as being geographically dispersed and remote. Implementation was also impacted where the initiative experienced substantial disruption (such as a change in LP) and where it took time to understand how to implement work guided by the Principles.

Table 1 shows that two communities were categorized as having had consistent quality implementation across all Building Blocks, while one community was categorized as having inconsistent quality implementation of all Building Blocks. All other communities had a mix quality in implementation of the Building Blocks. Similarities and differences in implementation between locations will be further discussed in another paper focusing on QCA.

\section{Case study themes}

Judgements for the qualitative indicators described above were shaped by the issues arising through the case study themes. Table 2, and the following section, illustrates some of the factors that facilitated and or impeded quality implementation.

\section{A flexible systems thinking and acting workforce}

I see systems change is looking for those tweaks or changes somewhere, that ... has a ripple effect somewhere else. And that everything is ... all connected and interrelated, and it's really about that continuous tweak here, adapt, tweak here, adapt ....

(Community 9, n 12)

Although recruitment and implementation has been variable across communities, we identified three key attributes of effective workforces. First, flexibility in skills of the workforce to meet local needs and adapt to change. Second was the ability to develop deep connections into diverse communities, while focusing on the bigger picture of systems-level change rather than service or programme delivery. Finally, the workforce needed to be highly skilled to facilitate strategic alignment between 
Table 2: Facilitating factors and areas for improvement in implementation by Prevention System Building Blocks

\begin{tabular}{|c|c|c|}
\hline & Facilitating factors & Areas for improvement \\
\hline Workforce & $\begin{array}{l}\text { - Team experiencing a good fit with LP. } \\
\text { - The guiding principles for action and value of equity. } \\
\text { - Professional development in leadership, co-design } \\
\text { methods, planning tools and evaluative practice. } \\
\text { - Willing collaborative partners and allies. } \\
\text { - National team making connections between communi- } \\
\text { ties and external organizations. } \\
\text { - National team responding effectively to local } \\
\text { challenges. }\end{array}$ & $\begin{array}{l}\text { - More professional development on systems } \\
\text { thinking and systems change. } \\
\text { - Difficulties with recruitment and staff turnover } \\
\text { in some areas. } \\
\text { - Greater clarity in the job descriptions of the } \\
\text { workforce. }\end{array}$ \\
\hline Leadership & $\begin{array}{l}\text { - Workforce empowered to lead and to access leaders. } \\
\text { - SLG providing direction on tailoring activities to local } \\
\text { needs. } \\
\text { - Resources being aligned with other local activities and } \\
\text { avoiding duplication. } \\
\text { - Amplifying work of teams through the spheres of } \\
\text { influence held by SLG members. } \\
\text { - More successful SLG's discussed they had strengthened } \\
\text { and increased the range of their own relationships. } \\
\text { - SLG regular meetings being viewed as productive and } \\
\text { worth the time. }\end{array}$ & $\begin{array}{l}\text { - Constraints to accessing and engaging decision- } \\
\text { makers. } \\
\text { - Unclear and inconsistent understanding amongst } \\
\text { SLG members of their role in supporting systems } \\
\text { change approach of the initiative. } \\
\text { - Lack of diversity in membership of the SLG and } \\
\text { inconsistent engagement of SLG members. } \\
\text { - Lack of clarity of why SLG were meeting or } \\
\text { perception that meetings were not productive. } \\
\text { - Need to establish a national-level SLG to enhance } \\
\text { cross-sector collaboration. }\end{array}$ \\
\hline $\begin{array}{l}\text { Relationships } \\
\text { and networks }\end{array}$ & $\begin{array}{l}\text { - Both workforce and SLG members leveraging pre- } \\
\text { existing relationships. } \\
\text { - The work of Healthy Families NZ in locations acted to } \\
\text { support and strengthen local relationships. } \\
\text { - Trust and understanding of the teams' work is growing } \\
\text { amongst other local organizations. } \\
\text { - Collaborations worked best when formed for a specific } \\
\text { activity. } \\
\text { - Overall positive and constructive relationship between } \\
\text { National and local teams. }\end{array}$ & $\begin{array}{l}\text { - Increase national-level collaborations for } \\
\text { collective action. } \\
\text { - More national actions to support local actions. } \\
\text { - Small community-based organizations relying on } \\
\text { volunteers or small number of paid staff found } \\
\text { collaborations outside core business challenging. } \\
\text { - Organizations running services funded by con- } \\
\text { tracts that focus on narrow performance targets } \\
\text { disincentivize collaborative initiatives. }\end{array}$ \\
\hline Resources & $\begin{array}{l}\text { - Teams' having flexibility in how resources are spent in } \\
\text { relation to workforce and priorities for local action. } \\
\text { - Other organizations having capacity to realign } \\
\text { resources as needs become clear. } \\
\text { - Often only small additional financial resource required, } \\
\text { with additional people to engage and coordinate new } \\
\text { connections a key enabling resource. }\end{array}$ & $\begin{array}{l}\text { - Siloed and competitive government funding pro- } \\
\text { cesses inhibit action on shared goals. } \\
\text { - Collaborating with small/stretched organizations } \\
\text { a limiting factor. }\end{array}$ \\
\hline $\begin{array}{r}\text { Knowledge } \\
\text { and data }\end{array}$ & $\begin{array}{l}\text { - Teams engaging in gathering local insights through } \\
\text { methods such as co-design and other participatory } \\
\text { approaches. } \\
\text { - Teams' utilizing methods such as surveys, interviews } \\
\text { or observational data designed to support evaluation } \\
\text { of particular initiatives. } \\
\text { - Development of capacity within teams for } \\
\text { developmental evaluation to improve and adapt } \\
\text { their work. }\end{array}$ & $\begin{array}{l}\text { - Establishing developmental evaluation practices } \\
\text { within the National team could enhance the } \\
\text { ability to reflect and respond to information and } \\
\text { feedback they receive from local teams. } \\
\text { - Strengthen local communications about stories of } \\
\text { change and effective evidence-based practices. } \\
\text { - Prioritizing and getting the right skills within the } \\
\text { team, leadership and embedding developmental } \\
\text { evaluation. } \\
\text { - The need for locally relevant quant and qual data } \\
\text { was considered very important in being able to } \\
\text { communicate stories of change. } \\
\text { - Need to improve the design of national-level data } \\
\text { sets, and analysis of these, which provide limited } \\
\text { support for community-level insights. }\end{array}$ \\
\hline
\end{tabular}


organizational and community leaders, gather local insights through a variety of methods, run co-design and co-production processes, tell the story of their work through strategic communications and evaluate initiatives for improvement through adaptation. During the 3 years, several local teams adapted their staffing mix towards more senior staff who could facilitate networks and engage diverse communities. In multiple communities, additional staffing resource was allocated to evidence-based local communications and evaluation.

\section{Active and adaptive leadership}

... we've been talking about, how do we go from business-as-usual conversations, to much more driving the long-term systems.

$$
\text { (Community 8, n 4) }
$$

Quality leadership was widely viewed as an essential ingredient to creating systems change. 'Quality' was seen as leaders being adaptive, as well as utilizing their own 'spheres of influence' to progress the goals of Healthy Families NZ. SLGs were more effective when members were in roles that allowed them to make decisions quickly to get their own organization actively involved.

The MoH National team was often recognized as responsive, supportive and helpful to local teams and SLGs. Tensions sometimes arose when they were seen to act as contractor and funder, rather than a partner. A strength of the National team sitting in SLGs was that they were able to immediately respond to issues arising and support the location teams.

\section{Relationships and networks (and resourcing) for collective action}

Collaboration is a really big one for us ... we don't want to go out and just do something by ourselvesbecause it is not sustainable.

$$
\text { (Community 5, n 4) }
$$

Almost all activities carried out by local teams were in collaboration with other organizations, often involving government-funded health and social service agencies, and also community non-governmental agencies, local government, Māori and Pasifika organizations. Teams found that the most useful organizational relationships and partnerships were purposeful and developed around specific activities. Consequently, they reported moving away from initial attempts to create large Prevention Partnerships, to instead focus on 'working with the willing' around more focused collaborations, on specific issues such as workplace well-being.

Teams also found themselves moving away from the original plan to work only with particular settings (such as schools or workplaces), and rather focused on connections between settings and sharing information, skills and practices. This was in part a response to the focus on innovation, with teams not wanting to replicate work, and to encountering the related impacts of other determinants of health, such as poverty. Participants frequently discussed challenges presented by the interconnected nature of social and environmental issues.

Collaborative working within the wider communities was seen to be generally increasing, but substantial constraints to effective collaborations remained. The modest resource available to community organizations clearly constrains what can be achieved, but less obviously the way these resources are delivered into communities appears to be a constraint. It appeared that siloed and competitive service funding approaches disincentivized organizations to cooperate on shared goals.

Achieving local action on alcohol challenged the teams. Community input and voice were disadvantaged in local alcohol licencing processes, while the interests of the alcohol industry were strongly favoured. A key enabler, however, has been local government connections, giving teams close access to policy that determines many aspects of the local environment. Mental health and well-being were consistently identified as unmet needs in the community, and being closely connected to health issues of focus.

\section{Locally relevant data, knowledge and stories of change}

We've embedded ourselves in communities to under-
stand what is going on-and that knowledge is so useful.
We look at an insight, and we've got local knowledge,
data, the voice of the participant ... we use those three
things strongly to build insight.

(Community 4, n 2)

The majority of local teams took time to prioritize and embed evaluation practices within their work planning. One challenge has been getting the right skills within the team, including leadership. Some teams found themselves with too many activities and opportunities for action, meaning systematic planning, reflection and evaluation was pushed to the side. This was explicitly recognized with most teams undertaking a process, during 2017, of revising how they worked and prioritized (also a sign of a systems thinking and acting workforce). 
Teams considered data at the local level very important to their ability to communicate stories of change. A commonly voiced frustration was the design of nationallevel data sets, and analysis of these, which provided limited support for community-level insights.

\section{Māori ownership and prioritizing equity}

It's approaching ... those kinds of issues from an indigenous perspective that's going to be palatable to communities who are going to own change.

(Community 2, n 2)

The design of Healthy Families NZ has resonated with traditional Māori world views and has enabled 'space' to be created for Māori perspectives on health. For example, there has been a movement towards 'Māori Systems Return', incorporating strengths-based approaches and Māori concepts and practices that have sustained well-being for Māori in the past. There has also been work within the teams utilizing Māori perspectives on the interrelationships between health and the environment.

The underlying Principles of the initiative are proving to be an effective mechanism for guiding both the workforce and SLGs on the activities, and methods, they should be prioritizing. Some improvements were suggested including broadening the set of Principles to include 'sustainability' and to be more specifically Māorifocused.

The principle of achieving equity, as a guiding value, has bonded many of those involved in the initiative and has also been prominent when prioritizing activities. Prioritizing equity has enabled the workforce to adapt initiatives to suit diverse communities, using deep local connections and methods such as co-design to promote and legitimize community perspectives on local health and well-being needs.

\section{DISCUSSION}

We are realising collaboration is hard. It takes a lot of time... to get everyone on the same waka [boat] and heading in the same direction .... Fruit Trees for Marae for example is an amazing piece of work where people are almost leaving their contracts behind and thinking, actually this is for our people.

(Community 5, n 1)

This article presents a summary of the numerous insights gained through evaluating a large-scale community programme of systems change for prevention in health. The strengths and limitations of the evaluation design have been described in detail elsewhere (Matheson et al., $2018 \mathrm{~b})$. However, one limitation worthy of mention here is the uncertainty about whether the initiative and its evaluation would have continued funding beyond the initial 4 years. This uncertainty impacted the initiative itself, meaning staff were lost, and different goals were set than might otherwise have been chosen with a longer-term view. For the evaluation, as intended, the design has enabled findings that are sensitive to context and identified what has worked and how. Our approach to the quantitative indicators might have differed, however, had we known the initiative was on-going. That said, key lessons in their development and communication have now been learned and can be utilized for the next time period.

\section{Normalizing a local systems change approach to prevention}

Healthy Families NZ continues to be implemented with integrity to its intention to create community systemschange with increasingly effective action, and adaptive learning occurring. Within the communities there is an evolution towards normalizing systems change as an approach to improving prevention and acting on health issues. The underpinning values of the initiative have helped set the scene for this evolution. Evidence for this change can be found closest to where the teams are located, in their influence on LPs and the MoH. This influence has seen the LPs becoming more health promoting and for some, like the Regional Sports Trusts, to be more focused on equity. One impediment to this shift has been some scepticism from others in the health sector about an approach that is not seen as the public health norm. Contemporary thinking about our big human system challenges-including those related to public health and health systems-increasingly argues that transforming systems requires changing social norms, and disrupting existing paradigms and power relationships (Swanson et al., 2012; Davies et al., 2014; Carey and Crammond, 2015; O'brien, 2018).

'Distributed' leadership is also argued as necessary for system transformation (Swanson et al., 2012). There is evidence of progress towards more joined-up community leadership for prevention. This is apparent through the SLGs, and the way local teams have been empowered to be, and have access to, leaders themselves. Challenges remain, however, for effectively activating local leadership due to practical reasons including difficulty connecting with the right people, 
and the reality that people are frequently heavily committed already. Similarly, although collaborative working within communities was found to generally be increasing, effectiveness was still a challenge. Siloed government investment strategies, in particular, seem to create a community environment not conducive to collective action.

\section{Flexibility and adaptation for diverse contexts}

The initiative was designed to be adaptive, but retaining this feature has required concerted effort at both the local and national levels. This ability to adapt activities to suit diverse communities has promoted and legitimized communities' perspectives on health. Moreover, there is increasing use of participatory methods such as codesign and an explicit focus on making deep local connections to amplify community needs and voice, which are needed to improve equity (Matheson et al., 2018a). This has been particularly useful for Māori communities involved, where action has been driven by traditional indigenous knowledge frameworks which strongly resonate with systems-oriented approaches (Oetzel et al., 2017; Heke et al., 2019).

The relationship between the National team and the local teams has enabled adaptation, through the flexibility of resources and narrative-style contract reporting rather than required reporting on specific targets. The relationship between the National team, and the local teams and SLGs, has allowed more immediate and responsive sharing of information.

Flexibility in the approach has also meant sanctioning of actions that address wider aspects of the environment and social connections, which have indirect but important influences on chronic disease risk factors. These issues include poverty, quality of built environments, drug use and addiction, family violence, access to affordable and healthy housing and mental health. Teams felt that these additional issues needed to be acted upon for action on the target chronic disease risk factors to be ultimately successful.

\section{Where to from here?}

It is tough work trying to consciously change systems to produce different social outcomes. It requires disruptive behaviour and directly addressing power relationships. The teams have not had an easy road getting to grips with how to achieve systems change. Moreover, the type of action required is high energy and needs emotional resilience and practical perseverance. Across communities some team members discussed feeling burnt out by the nature of the work they were involved in, as well as the uncertainty around its future. Some suggested these were reasons why they had decided to move on from Healthy Families NZ. Valuing the (largely women-dominated) workforce in terms of professional development and commensurate income has been important. The recognition of the high-level skills needed to create systems change within communities has been an eye-opener for many involved, including us as evaluators.

Furthermore, the relative stability of communities, in terms of both individuals and organizations, when compared to government organizations setting policy, points to a need for more effective ways of holding institutional knowledge and retaining memory of communities, within policy processes. This finding resonates with participatory policy approaches (Fischer, 2009; Innes and Booher, 2010).

There are positive signs from the $\mathrm{MoH}$ that recommendations resulting from the evaluation are being seriously considered, potentially strengthening and amplifying the efforts of the local teams. But there are still many hurdles to the initiative being successful in the longer-term. We know from the experience of improving CVD outcomes in North Karelia the importance of having the full suite of local and national, as well as population and targeted actions (Vartiainen, 2018). The reflections from numerous other large-scale health interventions tell us the importance of both context and relationships (Judge and Bauld, 2006; Matheson et al., 2009; Orton et al., 2017).

Healthy Families NZ is indeed an 'event within a system' (Hawe et al., 2009). The initiative design has explicitly taken into account the context of complexity within which it is being implemented. In doing so, it has evolved to focus on action that can accelerate sharing information within communities, and between policy and decision-makers, in an adaptive, responsive and deliberate way. Healthy Families NZ and its evaluation have been refunded to 2022. This provides an important opportunity to gather further insight into effective ways of strengthening the community agency and trust needed to promote, and deliver evidence-based action on prevention. The challenge now is whether momentum can be sustained, and the scope expanded in the longer-term.

\section{ACKNOWLEDGEMENTS}

We sincerely thank the members of the Healthy Families NZ national team within the Ministry of Health, all members of the Healthy Families NZ workforce, Lead Providers and Strategic Leadership Groups across the communities for their time and engagement with the evaluation, and all other participants who have generously given their time. Our thanks also to Dr Kirstin 
Lindberg and Mathu Shanthakumar from the Environmental Health Indicators programme for their commitment and insightful contribution to the evaluation. Our gratitude also goes to the members of the evaluation Māori advisory group: Dr Lis Ellison-Loschmann; Associate Professor Bridget Robson; Dr Amohia Boulton; Dr Heather Gifford.

\section{FUNDING}

The Evaluation of Healthy Families NZ has been funded by the New Zealand Ministry of Health.

\section{REFERENCES}

Adam, T., De Savigny, D., De Savigny, D., ProQuest \& World Health Organization. (2009) Systems Thinking for Health Systems Strengthening / Editors, Don De Savigny and Taghreed Adam.

Blackman, T., Wistow, J. and Byrne, D. (2011) A qualitative comparative analysis of factors associated with trends in narrowing health inequalities in England. Social Science \& Medicine, 72, 1965-1974.

Blackman, T., Wistow, J. and Byrne, D. (2013) Using qualitative comparative analysis to understand complex policy problems. Evaluation, 19, 126-140.

Braithwaite, J. (2018) Changing how we think about healthcare improvement. BMJ, 361, k2014.

Carey, G. and Crammond, B. (2015) Systems change for the social determinants of health. BMC Public Health, 15, 662.

Cheadle, A., Bourcier, E., Krieger, J., Beery, W., Smyser, M., Vinh, D. et al. (2011) The impact of a community-based chronic disease prevention initiative: evaluation findings from Steps to Health King County. Health Education \& Behavior, 38, 222-230.

Davies, S., Winpenny, E., Ball, S., Fowler, T., Rubin, J. and Nolte, E. (2014) For debate: a new wave of public health improvement. The Lancet (London, England), 384, 1889-1895.

De Leeuw, E. (2009) Evidence for Healthy Cities: reflections on practice, method and theory. Health Promotion International, 24, 119.

Eppel, E., Matheson, A. and Walton, M. (2011) Applying complexity theory to New Zealand public policy: principles for practice. Policy Quarterly, 7, 48-55.

Fischer, F. (2009) Democracy and Expertise: Reorienting Policy Inquiry. Oxford University Press, New York, NY.

Galea, G., Powis, B. and Tamplin, S. (2000) Healthy Islands in the Western Pacific-international settings development. Health Promotion International, 15, 169.

Greenhalgh, T. and Papoutsi, C. (2018) Studying complexity in health services research: desperately seeking an overdue paradigm shift. BMC Medicine, 16, 1-6.

Hawe, P. (2015) Lessons from complex interventions to improve health. Annual Review of Public Health, 36, 307-323.

Hawe, P., Shiell, A. and Riley, T. (2009) Theorising interventions as events in systems. American Journal of Community Psychology, 43, 267.
Heke, I., Rees, D., Swinburn, B., Waititi, R. T. and Stewart, A. (2019) Systems Thinking and indigenous systems: native contributions to obesity prevention. AlterNative: An International Journal of Indigenous Peoples, 15, 22-30.

Innes, J. and Booher, D. (2010) Planning with Complexity: An Introduction to Collaborative Rationality for Policymaking. Routledge, Oxon.

Judge, K. and Bauld, L. (2006) Learning from policy failure? Health Action Zones in England. European Journal of Public Health, 16, 341-344.

Matheson, A. (2016) Reducing social inequalities in obesity: complexity and power relationships. Journal of Public Health (Oxford, England), 38, 826-829.

Matheson, A., Bourke, C., Verhoeven, A., Khan, M., Nkunda, D., Dahar, Z. et al. (2018a) Lowering hospital walls to achieve health equity. BMJ, 362, K3597.

Matheson, A., Dew, K. and Cumming, J. (2009) Complexity, evaluation and the effectiveness of community-based interventions to reduce health inequalities. Health Promotion Journal of Australia, 20, 221-226.

Matheson, A., Walton, M., Gray, R., Lindberg, K., Shanthakumar, M., Fyfe, C. et al. (2018b) Evaluating a community-based public health intervention using a complex systems approach. Journal of Public Health, 40, 606-613.

Matheson, A., Walton, M., Gray, R., Lindberg, K., Shanthankumar, M. and Wehipeihana, N. (2018c) Summative Evaluation Report: Healthy Families NZ. M. E. Team. Ministry of Health, Wellington.

Murphy, J., Rhodes, M., Meek, J. and Denyer, D. (2017) Managing the entanglement: complexity leadership in public sector systems. Public Administration Review, 77, 692-704.

Nugent, R., Bertram, M. Y., Jan, S., Niessen, L., Sassi, F., Jamison, D. et al. (2018) Investing in non-communicable disease prevention and management to advance the Sustainable Development Goals. The Lancet, 391, 2029-2035.

O'brien, K. (2018) Is the $1.5^{\circ} \mathrm{C}$ target possible? Exploring the three spheres of transformation. Current Opinion in Environmental Sustainability, 31, 153-160.

Oetzel, J., Scott, N., Hudson, M., Masters-Awatere, B., Rarere, M., Foote, J. et al. (2017) Implementation framework for chronic disease intervention effectiveness in Māori and other indigenous communities. Globalization and Health, 13, 1-13.

Orton, L., Halliday, E., Collins, M., Egan, M., Lewis, S., Ponsford, R. et al. (2017) Putting context centre stage: evidence from a systems evaluation of an area based empowerment initiative in England. Critical Public Health, 27, 477-489.

Patton, M. Q. (2002) Qualitative Research and Evaluation Methods, 3rd edition. Sage, Thousand Oaks, CA.

Petticrew, M., Knai, C., Thomas, J., Rehfuess, E. A., Noyes, J., Gerhardus, A. et al. (2019) Implications of a complexity perspective for systematic reviews and guideline development in health decision making. BMJ Global Health, 4, e000899.

Rickles, D. (2009) Causality in complex interventions. Medicine, Health Care and Philosophy, 12, 77-90. 
Rutter, H., Savona, N., Glonti, K., Bibby, J., Cummins, S., Finegood, D. T. et al. (2017) The need for a complex systems model of evidence for public health. The Lancet, 390, 2602.

Salway, S. and Green, J. (2017) Towards a critical complex systems approach to public health. Critical Public Health, 27, 523-524.

Shiell, A., Hawe, P. and Gold, L. (2008) Complex interventions or complex systems? Implications for health economic evaluation. BMJ, 336, 1281-1283.

Stafford, M., Badland, H., Nazroo, J., Halliday, E., Walthery, P., Povall, S. et al. (2014) Evaluating the health inequalities impact of area-based initiatives across the socioeconomic spectrum: a controlled intervention study of the New Deal for Communities, 2002-2008. Journal of Epidemiology and Community Health, 68, 979-986.

Swanson, R., Cattaneo, A., Bradley, E., Chunharas, S., Atun, R., Abbas, K. et al. (2012) Rethinking health systems strengthening: key systems thinking tools and strategies for transformational change. Health Policy and Planning, 27, iv54-61.

Tremblay, M. and Richard, L. (2014) Complexity: a potential paradigm for a health promotion discipline. Health Promotion International, 29, 378-388.

Vartiainen, E. (2018) The North Karelia Project: cardiovascular disease prevention in Finland. Global Cardiology, Science and Practice, 13.

Walton, M. (2014) Applying complexity theory: a review to inform evaluation design. Evaluation and Program Planning, $45,119-126$.

Warren, J., Wistow, J. and Bambra, C. (2014) Applying qualitative comparative analysis (QCA) in public health: a case study of a health improvement service for long-term incapacity benefit recipients. Journal of Public Health, 36, 126-133. 